\title{
Silica Animal Model for Autoimmune Disease and The \\ Potential Use of Myrrh Compared with The Conventional Treatment
}

Dina E. EIMosbah; Marwa S. Khattab*; Hala M. F. El Miniawy Department of Pathology, Faculty of Veterinary Medicine, Cairo University, Giza, 12211, Egypt

* Correspondence, E-mail: Marwakhattab@cu.edu.eg

\section{Abstract}

Autoimmune diseases(AD) result from the breakdown of selftolerance where the immune system attacks self-antigens leading to multiple organ failure. It affects animals and humans. Genetic predisposition and environmental factors influence the development of AD. For understanding disease pathogenesis and developing immunotherapeutic strategies, several animal models have been developed. Spontaneous and induced animal models of autoimmune diseases were used. The Induced autoimmune models involved the use of experimental infections, drugs, chemicals, metals, and environmental substances. Among the environmental substances that raise a concern and act as a potential candidate for use in an autoimmune animal model is silica. Nowadays, the use of natural compounds is gaining wide popularity since it's a safer and cheaper source of drugs. The relation between silica and autoimmune disease is discussed in this review. Furthermore, various treatment options are reviewed which include available medications and possible natural antiinflammatory compounds. Myrrh as a natural medicine possessing anti-inflammatory properties makes it a possible conjunctive treatment to autoimmune diseases.

Key words: Silica, Animal Model, Autoimmune Disease, Myrrh, Conventional Treatment

\section{Introduction}

The immune system of humans and animals can be either useful or harmful based on its ability to distinguish between self and non-self-antigens. Any disorder in the recognition of antigens leads to autoimmunity. Autoimmune disorders result from the attack of immune cells and antibodies to cells, tissues, and organs (Ganapathy et al., 2017). 
Autoimmune diseases (AD) are either organ-specific or systemic diseases (Lam-Tse et al., 2002). The systemic

lupus erythematosus (SLE), scleroderma, and inflammatory myopathies are examples of systemic autoimmune diseases.

The key therapeutic approach of autoimmune disorders is the suppression of the autoimmune response using antiinflammatory and immunosuppressive therapy. They subside the immune activation and subsequent inflammatory damage by targeting several cytokines and cells crucial in the inflammatory process (Dalakas., 2006).

In this review, we attempt to review the different models of autoimmune diseases, the relation of silica and development of $\mathrm{AD}$, and the treatment options of autoimmune diseases especially the herbal remedy myrrh.

\section{Etiology of autoimmune diseases}

Autoimmune diseases are initiated by multiple factors including environmental, genetic, and hormonal factors. Intrinsic factors as age, sex, and genetics and extrinsic factors as chemicals, drugs, microbes, and/or the environment can elicit an autoimmune response. The mechanism by which these factors trigger the immune response is still perplexing (Pollard et al., 2010).

There are over 70 different medications and environmental substances that are thought of as a potential cause of these diseases. This includes tartrazines, hair dyes, hydrazines, trichloroethylene, hazardous wastes, L canavanine, silica, mercury, cadmium, and gold (Hess, 2002).

Animal models for autoimmune diseases

To study the effect of autoimmune diseases on body systems and the different strategies for treatment, it was necessary to develop animal models for such diseases. Autoimmunity can be triggered in prone and non-prone strains of animal models by different mechanisms which include chemical, physical, or biological factors or immunization with specific (auto) antigen (Andersson and Karlsson, 2004; Germolec et al., 2012).

Experimental animal models are the best way to unleash the mechanisms of autoimmune diseases. The rats and mice are now the most commonly used species for experimental medicine. There are three main categories of autoimmune animal models that are used; genetically engineered models, induced models, and spontaneous models. Spontaneous models such as 
non-obese diabetic (NOD) mouse, which developed type 1 diabetes, and New Zealand White mixed mouse (NZW) which developed a lupus-like disease (Morel, 2004). Spontaneous models however don't exist for all human autoimmune diseases, therefore induced models were developed like collagen-induced arthritis models by streptococcal wall transfer or passive antibody (Brand et al., 2007).

Certain infections were linked with the development of specific autoimmune diseases. This association allowed the development of an autoimmune animal model. Myocarditis, for instance, was induced by group A streptococci cutaneous injections in rabbits (Murphy and swift, 1949), injection of bacterial antigens of streptococci in multiple strains of mice (Cunningham, 2001), and injection of antibodies against streptococcal M protein (Gorton et al., 2009). Furthermore, rheumatoid arthritis was induced by heat shock proteins of several mycobacterium strains (Yoshitomi et al., 2005). Autoimmune encephalomyelitis was also successfully induced by a viral infection like Theiler's murine encephalomyelitis (Pordeus et al., 2008). Some parasitic infections also as Trypanosoma cruzi was used to induce Chagas' disease cardiomyopathy (Tarleton et al., 2007).

A large list of drugs develops SLE-like disease especially procainamide and hydralazine (Rubin, 2005). Drugs like TNFa antagonists were able to induce various types of autoimmunity (Dedeoglu, 2009). A murine model of lupus was developed using procainamide (KretzRommel et al., 1997).

Many environmental substances suspected of causing autoimmunity were studied in animal models. Chemical induced autoimmune disease was studied in animals to elucidate their mechanism of action. The halogenated aromatic hydrocarbon 2,3,7,8tetrachlorodibenzo-p-dioxin

which results mainly from burning processes of organic materials was used experimentally in NFS/sld mice to clarify the role of the neonatal thymus in developing the autoimmune disease (Ishimaru et al., 2009).

Trichloroethylene (TCE), its derivatives and fungicide hexachlorobenzene HCB were also involved in inducing and/or exacerbating human and animal autoimmunity (Cooper et al., 2009). Brown Norway rats exposed to $\mathrm{HCB}$ showed that HCB can activate macrophages with the release of proinflammatory cytokines besides activating $\mathrm{T}$ and $\mathrm{B}$ cells causing 
lung eosinophilia and skin lesions (Ezendam et al., 2005). The lupus-like disease was also enhanced by organochlorine pesticides in a susceptible mouse strain (Sobel et al., 2006).

Mineral oil and related substances induce an autoimmune response in animal models since they are potent proinflammatory agents and adjuvants (Reeves et al., 2009). Subcutaneous injection of rats with a component of mineral oil, 2,6,10,14-

tetramethylpentadecane (TMPD or pristane), and its intraperitoneal injection in $\mathrm{BALB} / \mathrm{c}$ mice lead to chronic inflammatory arthritis (Olofsson and Holmdahl, 2007). Mice and rats treated with TMPD exhibited a lot of the signs of human SLE and human RA respectively (Reeves et al., 2009).

Other environmental substances used in animals to induce autoimmunity include asbestos (Pfau et al., 2008), and UV radiation (Menke et al., 2008). High dietary consumption of iodine increased thyroid autoimmunity incidence in thyroiditis-prone $\mathrm{BB}$ rats and genetically predisposed NOD.H2h4 mice (Mooij et al., 1993; Teng et al., 2009). Mercury was also studied in experimental animal models. Dental amalgams implantation in molars of $\mathrm{BN}$ rats and Lewis rats was shown to activate polyclonal B cells, elevate IgE, and $\mathrm{IgG}$ renal deposition in $\mathrm{BN}$ rats only (Hultman et al., 1998). Similarly, different mice strains responded differently to mercury (Vas and Monestier., 2008). Mercuric chloride was used in a collagen-induced model to exacerbate the onset and severity of arthritis (Hansson et al., 2005). Silver nitrate and silver alloy induced autoantibodies in mice without antigen-antibody complex deposition (Hultman et al., 1995; Pollard et al., 2010). So, mercury is more efficient in inducing autoimmunity than silver (Pollard et al., 2010).

Gold salts can also induce autoimmune diseases in certain strains of mice with variable ANA and humoral responses (Havarinasab et al., 2007). The gold activated polyclonal B cell and induced IgE, autoantibodies, vasculitis, and glomerulonephritis in Brown Norway (BN) rats (Qasim et al., 1997).

\section{Silica and autoimmunity}

Silica is distributed widely in sand, soil, rock, and constitute a small particulate fraction of air pollution (Pollard, 2016). Silica dust is considered an occupational hazard in many construction and manufacturing processes like mining, stone cutting, foundry work, glass manufacture, vitreous enameling, porcelain, and lining 
bricks. Silica sand is also incorporated in many compounds as paints, detergents, plastics, and cement (Pollard, 2016). Recently, nano-silica or silica nanoparticles (SiNPs) were used in various biomedical applications such as molecular imaging and drug delivery (Tang and Cheng, 2013). Nevertheless, SiNPs showed acute toxic effects in experimental studies (Murugadoss et al., 2017). Also, many medical devices including breast, joints, tubing, intraocular lenses, and artificial heart valves contain biologically inert silicone. However mild foreign body reaction and encapsulation were recorded due to silicone implant. Furthermore, studies showed an association between autoimmune disease and silicone breast implants (Levy et al., 2009).

Crystalline silica exposure can develop many autoimmune diseases such as Sjögren's syndrome, rheumatoid arthritis (RA), systemic sclerosis (SSc), and systemic lupus erythematosus (SLE), (AlMogairen, 2011). The risk of these diseases was shown to be higher in silica-exposed population compared with nonexposed populations (Ghahramani, 2010). Furthermore, cases of autoimmune hemolytic anemia, dermatomyositis, and Graves' disease with a history of high- level silica exposure were reported (Steenland et al., 1995). It seems that silica exposure causes mainly generalized autoimmune diseases with inflammation of various organs like blood vessels, joints, skin, and kidneys (Pollard, 2016).

Pathophysiology of silicainduced autoimmunity

Silica exposure can lead to autoimmunity progression through the activation of the innate immune system with subsequent pro-inflammatory cytokine release. It causes pneumonia resulting in the activation of adaptive immunity activation (Brown et al., 2005). The continued activation of responder Thelper cells and Fasmediated apoptosis of regulatory $\mathrm{T}$ cells as a result of silica exposure play a key role in breaking tolerance. The responder Thelper cells express and produce various molecules such as soluble Fas which inhibit Fas-mediated apoptosis with the survival of self-reactive immune cells (Otsuki et al., 1998). Moreover, excess self-antigen presentation due to necrosis or apoptosis on antigen-presenting cells (APC) also shares in breaking tolerance. Various auto-antigens like nucleosomal components become bare on apoptotic cells (Rosen and Casciola-Rosen, 1999). 
Interestingly, the crystalline silica is cleared by scavenger receptor known as macrophage receptor with collagenous structure (MARCO) and its modulation could affect the severity of systemic autoimmune diseases (Thakur et al., 2009; Rogers et al., 2009).

Silica can also activate circulating mononuclear cells, microvascular endothelial cells, and dermal fibroblasts which may play a role in the development of the scleroderma in people exposed to silica (Hess, 2002).

Silica induced autoimmune disease model

Few animal studies used silica to induce autoimmunity. Crystalline silica exposure in lupus-susceptible New Zealand mixed NZM2410 mice resulted in pneumonia, fibrosis, elevated autoantibodies, and renal IgG and $\mathrm{C} 3$ deposits compared to controls (Brown et al., 2003). These autoantibodies can bind favorably to apoptotic macrophages (Pfau et al., 2004). The exacerbation of systemic lupus erythematosus SLE disease associated with inducible bronchus-associated lymphoid tissue (BALT) was confirmed in lupus-prone NZBWF1 mice (Bates et al., 2015). Furthermore, Non-prone Brown Norway rats subcutaneously injected with sodium silicate developed a significant number of rats with high antinuclear antibodies (ANA) titer compared to the oral silicate group which had a few rats with positive titer (Al-Mogairen et al., 2009).

Treatment of autoimmune diseases

The therapy of autoimmune disorders aims mainly to suppress the immune activation and hence reduce the inflammatory damage by antiinflammatory and immunosuppressive therapy. The therapy targets several cytokines and cells which take part in the continued inflammatory process (Dalakas, 2006).

Non-steroidal antiinflammatory drugs (NSAIDs):

The NSAIDs include various drugs such as Aspirin, Ibuprofen, and Naproxen which mostly target and suppress prostaglandins (PGs) by inhibiting cyclooxygenase (COX) enzymes. Unfortunately, NSAIDs have side effects with hepatic, renal, and cardiovascular toxicity. Myocardial infarction and stroke were reported with certain COX2-selective agents (Crofford, 2013).

\section{Corticosteroids:}

Corticosteroids are among the most commonly prescribed drugs in autoimmune diseases especially the systemic ones due to their rapid and broad- 
spectrum actions on immune cells (van der Goes et al., 2014). Corticosteroids bind to the glucocorticoid receptor (GR), also called nuclear receptor subfamily 3 group $\mathrm{C}$ member 1 (NR3C1), causing multiple gene transcription and inhibition of various inflammatory pathways. Furthermore, corticosteroids can result in epigenetic modification of histones with the subsequent subsiding of inflammation (Barnes, 2006). Corticosteroids have many drawbacks such as osteoporosis, glaucoma, and metabolic abnormalities such as diabetes and hypercholesterolemia (van der Goes et al., 2014). Besides, highdoses can also result in osteonecrosis and metal disorders (Kopf et al., 2010). Also, corticosteroid long therapy can cause centrilobular ballooning degeneration, hepatic steatosis, and hepatic enlargement as in alcoholic hepatitis, chronic inflammation, and Mallory bodies (Candelli et al., 2003).

Prednisolone is one of the corticosteroids, it is considered among the top 10 most prescribed drugs (Hillier, 2007). In vivo studies confirmed its anti-inflammatory actions in induced SLE model in female NZB/W mice (Chafin et al., 2013), and zymosan model of acute peritonitis in male Swiss albino mice (Paul-Clark et al.,
2000). Due to the side effects of corticosteroids, novel therapeutic approaches for autoimmune diseases have been investigated to lessen or even eliminate the need for steroids.

Immunosuppressive therapies: A dose of $10 \quad \mathrm{mg}$ prednisolone/day or even more is required to manage moderate to severe autoimmune disease. This dose is considered very high and has many side effects. Therefore, other immunosuppressive agents are used to lessen the dose of steroids and at the same time suppress the ongoing inflammatory process and prevent organ damage (Maame et al., 2010).

Azathioprine for instance is commonly used to treat mild-tomoderate disease. It inhibits the proliferation of lymphocytes, suppresses natural killer cell activity, and reduces antibody production, therefore, subsiding the cell-mediated and humoral immune responses. It is also used as maintenance therapy in severe cases and improved the disease outcome as observed in lupus nephritis trials (Mok et al., 2004).

Cyclophosphamide is an alkylating agent that kills cells at any stage of mitosis resulting in depletion of $\mathrm{B}$ and $\mathrm{T}$ cells and subsequent reduction of autoantibodies production. cyclophosphamide was more beneficial for the treatment of 
lupus nephritis than high dose corticosteroids as reported by the National Institutes of Health (NIH) (Austin et al., 1986).

Nevertheless, the drawbacks of cyclophosphamide are plenty including myelotoxicity, ovarian failure, reversible hair loss, nausea, and severe bacterial infections (Blumenfeld et al., 2000). The alkylating agent can also increase the risk of malignancy (Stillwell et al., 1988) and can't be used during pregnancy due it is a teratogenic effect (Østensen et al., 2006).

\section{Antimalarial drugs:}

Antimalarial drugs such as mepacrine, chloroquine, and hydroxychloroquine were used to treat SLE for many years. Chloroquine sulfate and phosphate are now rarely used due to increased risk of ocular toxicity. Mepacrine can treat lupus-induced skin rashes but is not useful on other signs (Fessler et al., 2005).

HCQ therapy was useful in the treatment of SLE. It decreased disease activity, glomerulonephritis, and renal damage (Lee et al., 2011). Besides, HCQ treatment decreased serum creatinine and IgG production in rheumatoid arthritis patients (Landewe et al., 1995).

The mechanism of action of Hydroxychloroquine (HCQ) was suggested to be due to the elevation of intracytoplasmic and lysosomal $\mathrm{pH}$ so disturbing the leukocytes function. Consequently, the production of cytokines and the processing of antigens is reduced due to a reduction in the number of cell surface receptors (Jeong et al., 2002). The processes of chemotaxis and phagocytosis are also decreased (YildirimToruner and Diamond, 2011) and the formation of the immune complex is inhibited in vivo by HCQ due to DNA binding (Segal-Eiras et al., 1985).

\section{Biologic therapy:}

The biologic therapies are promising because they are safe, efficient, and are well studied. Their mode of action and the initial immunological targets in many diseases are well understood. The current drawbacks of biologic therapies include the adverse effect of these drugs, the high cost, and the inconvenience of intravenous (IV) administration. The biologic therapies mainly target $\mathrm{B}$ cells, cytokines, and costimulation molecules. B-cells can be depleted by the use of anti-CD20 antibodies and modulation of $\mathrm{B}$ cell receptor (BCR) by the B-lymphocyte stimulator (BLyS). Anticytokines contain antiinterleukin (IL)-1, anti-tumor necrosis factor (TNF)- $\alpha$, and anti-IL-6 molecules. Examples of Biologic therapy are rituximab, tocilizumab, 
of atumumab belimumab, golimumab, and sifalimumab.

Tocilizumab (TCZ) is a recombinant monoclonal $\mathrm{IgG} 1$ anti-human IL-6 receptor (IL6R) antibody (Burmester et al., 2011). Experimentally, TCZ injection into the inflamed joints decreased the inflammation and joint swelling (Uchiyama et al., 2008).

Rituximab is a chimeric human monoclonal antibody against CD20 protein present on types of B cells. Rituximab causes cellular cytotoxicity, and apoptosis of B cells leading to depletion of B cell population (Verweij and Vosslamber., 2011).

Ofatumumab is a fully human monoclonal antibody directed against the membrane-proximal epitope on the CD20 molecule. It is indicated for the treatment of RA and chronic lymphocytic leukemia (Taylor et al., 2011).

Natural plant Products (herbal medicine) for autoimmune Therapy:

Although the previously mentioned drugs are the most commonly prescribed to autoimmune disease patients, they still have plenty of side effects. Therefore, alternative sources of drugs are still being investigated such as natural compounds. Natural plants can be a safe and cheap source of drugs (Shalaby et al., 2014).
Natural products having an antiinflammatory effect act through many pathways. They can inhibit effector molecules such as chemokines and proinflammatory cytokines, or encourage anti-inflammatory mediators production like IL-4, and IL-10, or adjust the balance between Thelper17 and $\mathrm{T}$ regulatory (Astry et al., 2015).

We review below some of the natural products tested in animal models for the treatment of autoimmune diseases principally rheumatoid arthritis.

Tripterygium wilfordii Hook $F$ (TwHF):

TwHF is a Chinese herb often known as thunder god vine. It can suppress numerous proinflammatory mediators. TwHF extract can reduce $\mathrm{COX}-2$ expression leading to a decrease in prostaglandin E2 (PGE2) production in vitro (Bao and Dai, 2011). Also, TwHF targets and suppresses the transcription of the inducible nitric oxide synthase (iNOS) gene which in turn inhibits the production of nitric oxide (NO) (Guo et al., 2001).

Green Tea:

Green tea (Camellia sinensis) possesses various antiinflammatory properties. It reduced serum TNF- $\alpha$ and IL-1 $\beta$ proinflammatory cytokine in rats (Ramadan et al., 2017). Epigallocatechin-3-gallate (EGCG) in green tea is believed 
to be the bioactive molecule that targets several inflammatory pathways (Bhutia Pemba et al., 2015).

\section{Curcumin:}

It also has anti-inflammatory properties. Curcumin is one of the bioactive components of turmeric (Curcuma longa) which attenuate inflammation (Gupta et al., 2013). Curcumin was efficient in treating arthritis of the adjuvant induced arthritis model in Lewis rats (Zheng et al., 2015).

\section{Resveratrol:}

Resveratrol used in CIA mice was able to reduce arthritis. These mice had an improved $\mathrm{T}$ cell profile with a decrease in the number of Th17 cells and low levels of IL-17, and CII-specific antibodies (Coradini et al., 2015).

\section{Celastrus}

It is traditional Chinese medicine, which has been used for many decades for the treatment of inflammatory diseases including arthritis. A major effect of Celastrus is the inhibition of IL-1 $\beta$, IL-6, IL-17, and IL-18 cytokines (Tong and Moudgil, 2007).

Myrrh

It is the oleo-gum resin found in the stem of Commiphora molmol. It is known to possess analgesic, anti-microbial, antioxidant, and anti-inflammatory properties (Rosenthal et al., 2017). It has been used in the past to treat many diseases such as fever, ulcerative colitis, ailments of the gall bladder, amenorrhea, chest ailments, skin infections, and in burn treatment (Pec'anac et al., 2013). Besides myrrh resin was used in cases of arthritis, tumors, trauma, and fractures with improvement in blood circulation (Shen et al., 2012). Furthermore, the U.S Food and Drug Administration approved the safety of myrrh.

The guggulsterone, a myrrh component, was found to downregulate some inflammatory mediators like IFN- $\gamma$, TNF $\alpha$, IL-1 $\beta$ or IL- 2 , and inhibit MAP kinases like c-jun NH2-terminal kinase (JNK) pathway and p38 in peripheral mononuclear cells (Rosenthal et al., 2017). Moreover, Myrrh has Myrrhanol A (polypodane triterpenoid) which possessed a potent anti-inflammatory effect even more than hydrocortisone in adjuvant-induced air pouch granuloma model (Shen et al., 2012). Also, sesquiterpenoids component Elema-1,3,11(13)trien-12-ol has an immunomodulatory effect as reported in invitro studies (Kim et al., 2013). Myrrh plays also an important role against oxidative damage associating diseases (Forman et al., 2013) and possesses other biological activities like antibacterial, antifungal (Kim et al., 2013) and 
antiparasitic activity (AbdulGhani et al., 2009).

Several studies on animal models confirm the antiinflammatory effect of myrrh (Shalaby et al., 2014). The myrrh extract at a dose of 3.9 $\mathrm{g} / \mathrm{kg}$ in mice inhibited the formalin-induced paw edema. Besides, the Commiphora myrrha extract showed analgesic activities (Su et al., 2012). Myrrh treatment showed antiinflammatory effects on LPS (Lipopolysaccharide)-stimulated macrophages and antimicrobial sepsis on CLP (cecal ligation and puncture) (Kim et al., 2012). Myrrh attenuated oxidative and inflammatory processes in an acetic acid-induced ulcerative colitis model (Fatani et al., 2016). Furthermore, the efficacy of individual and combined extracts of Frankincense and Myrrh resin was assessed against adjuvant-induced arthritis (AIA) in Sprague-Dawley (SD) rats ( $\mathbf{S u}$ et al., 2015).

\section{Other Natural Products}

There are many other natural products such as Boswellia serrate, Rosa canina, Zingiber officinale which have antiinflammatory activities and showed a beneficial effect in the treatment of autoimmune diseases in patients and experimental models (Chrubasik et al., 2008; Ammon, 2010; Semwal et al., 2015).

\section{Conclusion}

$\mathrm{AD}$ is still one of the most widespread diseases with various etiologies. Presently, animal models remain one of the crucial tools for the understanding and creation of knowledge regarding autoimmune diseases. Environmental substances such as silica have an underestimated role in the initiation of AD. The current approach of managing $\mathrm{AD}$ has not yet achieved the desired results. Hence, a treatment protocol based on combination therapies of drugs and natural compounds should be explored to enhance the therapeutic efficacy and reduce the side effects of current approaches.

\section{References}

Abdul-Ghani RA, Loutfy N, Hassan A. (2009): Myrrh and trematodoses in Egypt: an overview of safety, efficacy, and effectiveness profiles. Parasitol Int, 58: 210-214.

Ahamad SR, Al-Ghadeer AR, Ali R, et al. (2017): Analysis of inorganic and organic constituents of myrrh resin by GC-MS and ICP-MS: An emphasis on medicinal assets. Saudi Pharm J, 25: 788-794.

Al-Mogairen SM. (2011): Role of Sodium Silicate in Induction of Scleroderma-Related Autoantibodies in Brown 
Norway Rats through Oral and Subcutaneous Administration. Rheumatol Int, 31: 611-15.

Al-Mogairen SM, Al-Arfaj AS, Meo SA, et al. (2009): Induction of autoimmunity in Brown Norway rats by oral and parenteral administration of sodium silicate. Lupus, 18: 4137.

Ammon HP(2010): Modulation of the immune system by Boswellia serrata extracts and boswellic acids. Phytomedicine, 17: 862-867.

Andersson A and Karlsson J. (2004): Genetics of experimental autoimmune encephalomyelitis in the mouse. Arch Immunol Ther Exp (Warsz), 52: 316-25.

Astry B, Venkatesha SH, Laurence A, et al. (2015): Celastrol, a Chinese herbal compound, controls autoimmune inflammation by altering the balance of pathogenic and regulatory $\mathrm{T}$ cells in the target organ. Clin. Immunol, 157: 228238.

\section{Austin HA, Klippel JH, Balow} JE, et al. (1986): Therapy of lupus nephritis. Controlled trial of prednisone and cytotoxic drugs. N Engl J Med, 314: 614619.

Bao J and Dai SM. (2011): A Chinese herb Tripterygium wilfordii Hook F in the treatment of rheumatoid arthritis: Mechanism, efficacy, and safety. Rheumatol Int, 31: 1123-1129.

Barnes PJ (2006): How corticosteroids control inflammation: Quintiles Prize Lecture 2005. Br J Pharmacol, 148: 245-254.

Bates MA, Brandenberger C, Langohr I, et al. (2015): Silica triggers inflammation and ectopic lymphoid neogenesis in the lungs in parallel with accelerated onset of systemic autoimmunity and glomerulonephritis in the lupusprone NZBWF1 mouse. PLoS One, 10: e0125481.

Bhutia Pemba H, Sharangi AB, Lepcha R, et al. (2015): Bioactive Compounds and Antioxidant Properties of Tea: Status, Global Research and Potentialities. J Tea Sci Res, 5: 1-13.

Blumenfeld Z, Shapiro D, Shteinberg M, et al. (2000): Preservation of fertility and ovarian function and minimizing gonadotoxicity in young women with systemic lupus erythematosus treated by chemotherapy. Lupus, 9: 401405.

Brand DD, Latham KA, Rosloniec EF. (2007): Collagen-induced arthritis. Nat Protoc, 2: 1269-75. 
Brown JM, Archer AJ, Pfau JC, et al. (2003): Silica accelerated systemic autoimmune disease in lupusprone New Zealand mixed mice. Clin Exp Immunol, 131: 415421.

Brown JM, Pfau JC, Pershouse MA, et al. (2005): Silica, apoptosis, and autoimmunity. J Immunotoxicol, 1: $177-87$.

Burmester GR, Feist E, Kellner H, et al. (2011): Effectiveness and safety of the interleukin 6-receptor antagonist tocilizumab after 4 and 24 weeks in patients with active rheumatoid arthritis: the first phase IIIb real-life study (TAMARA). Ann Rheum Dis, 70: 755-759.

Candelli M, Nista EC, Pignataro G, et al. (2003): Steatohepatitis during methylprednisolone therapy for ulcerative colitis exacerbation. $\mathbf{J}$ Intern Med, 253:391-2.

Chafin CB, Regna NL, Hammond SE, et al. (2013): Cellular and urinary microRNA alterations in NZB/W mice with hydroxychloroquine or prednisone treatment. Int immunopharmacol, 17:894-906.

Chrubasik C, Roufogalis BD, Muller-Ladner U et al. (2008): systematic review on the Rosa canina effect and efficacy profiles. Phytother Res, 22: 725 733.

Cooper GS, Makris SL, Nietert PJ, et al. (2009): Evidence of autoimmune-related effects of trichloroethylene exposure from studies in mice and humans. Environ Health Perspect, 117: 696-702.

Coradini K, Friedrich RB, Fonseca FN, et al. (2015): A novel approach to arthritis treatment based on resveratrol and curcumin co-encapsulated in lipid-core nanocapsules: In vivo studies. Eur. J. Pharm. Sci., 78: 163-170.

Crofford LJ. (2013): Use of NSAIDs in treating patients with arthritis. Arthritis Res Ther, 15 : $\mathrm{S} 2$.

Cunningham MW. (2001): Streptococcus-induced myocarditis in mice. Autoimmunity, 34: 193-7.

Dalakas MC. (2006): Therapeutic targets in patients with inflammatory myopathies: Present approaches and a look to the future. Neuromuscul Disord, 16: 223-36.

Dedeoglu F. (2009): Druginduced autoimmunity. Curr Opin Rheumatol, 21: 547-51.

Ezendam J, Vos JG, Pieters R. (2005): Research articles mechanisms of hexachlorobenzene-induced adverse immune effects in brown 
norway rats. J Immunotoxicol, 1: 167-75.

Fatani AJ, Alrojayee FS, Parmar MY, et al. (2016): Myrrh attenuates oxidative and inflammatory processes in acetic acid-induced ulcerative colitis. Experim Ther Med, 12: 730738.

Fessler BJ, Alarco 'n GS, McGwin G, et al. (2005): Systemic lupus erythematosus in three ethnic groups: XVI. Association of hydroxychloroquine use with reduced risk of damage accrual. Arthritis Rheum, 52: 1473-1480.

Forman HJ, Davies KJ, Ursini F. (2013): How do nutritional antioxidants really work: nucleophilic tone and parahormesis versus free radical scavenging in vivo. Free Radical Biol Med, 66: 24-35.

Ganapathy S, Vedam V, Rajeev V, et al. (2017): A novel and Rapid LC-MS/MS assay for the Determination of Mycophenolate and Mycophenolic Acid in Human Plasma. J Young Pharm, 9: 1422.

\section{Germolec DR, Kono DH, Pfau} JC, et al. (2012): Animal models used to examine the role of the environment in the development of autoimmune disease: Findings from a National Institute of Environmental Health Sciences
Expert Panel Workshop. J Autoimmun, 39: 285-293.

Ghahramani N. (2010): Silica Nephropathy. Int $\mathbf{J}$ Occup Environ Med, 1: 108-15.

Gorton D, Govan B, Olive C, et al. (2009): B- and T-Cell Responses in Group A Streptococcus M-Protein- or Peptide-Induced Experimental Carditis. Infect Immun, 77: 2177-2183.

Guo W, Ma L, Tao X. (2001): In vitro inhibitive effects of Tripterygium wilforii on NO production, iNOS activity, and iNOS-mRNA expression in chondrocyrtes of patients with rheumatoid arthritis. Zhonghua Yi Xue Za Zhi, 81: 1035-1037.

Gupta SC, Kismali G, Aggarwal BB. (2013): Curcumin, a component of turmeric: From farm to pharmacy. Biofactors, 39: 2-13.

Hansson M, Djerbi M, Rabbani H, et al. (2005): Exposure to mercuric chloride during the induction phase and after the onset of collageninduced arthritis enhances immune/autoimmune responses and exacerbates the disease in DBA/1 mice. Immunology, 114: 428-37.

Havarinasab S, Johansson U, Pollard KM, et al. (2007): Gold causes genetically determined autoimmune 
immunostimulatory responses in mice. Clin Exp Immunol, 150: 179-88.

Hess EV (2002): Environmental chemicals and autoimmune disease: cause and effect. Toxicology, 181: 65-70.

Hillier SG. (2007): Diamonds are forever: the cortisone legacy. JEndocrinol, 195: 1-6.

Hultman P, Ganowiak K, Turley SJ, et al. (1995): Genetic susceptibility to silver-induced antifibrillarin autoantibodies in mice. Clin Immunol Immunopathol, 77: 291-7.

Hultman P, Lindh U, HorstedBindslev P. (1998): Activation of the immune system and systemic immunecomplex deposits in Brown Norway rats with dental amalgam restorations. J Dent Res, 77: 1415-25.

Ishimaru N, Takagi A, Kohashi M, et al. (2009): Neonatal Exposure to Low-Dose 2,3,7,8-Tetrachlorodibenzo-pDioxin Causes Autoimmunity Due to the Disruption of T Cell Tolerance. J Immunol, 182: 6576-6586.

Jeong JY, Choi JW, Jeon KI, et al. (2002): Chloroquine decreases cell-surface expression of tumour necrosis factor receptors in human histiocytic U-937 cells. Immunology, 105: 83-91.
Kim MS, Bae GS, Park KC, et al. (2012): Myrrh inhibits LPSinduced inflammatory response and protects from cecal ligation and puncture-induced sepsis. Evid based Complement Altern Med, 2012: 278718.

Kim CH, Lee T, Oh I, et al. (2013): Mast cell stabilizing effect of (-)-Elema-1,3,11(13)trien-12-ol and thujopsene from Thujopsis dolabrata is mediated by down-regulation of interleukin-4 secretion in antigen-induced RBL-2H3 cells. Biol Pharm Bull, 36: 339-345.

Kopf M, Bachmann MF, Marsland BJ, et al. (2010): Averting inflammation by targeting the cytokine environment. Nat Rev Drug Discov, 9: 703-718.

Kretz-Rommel A, Duncan SR, Rubin RL. (1997): Autoimmunity caused by disruption of central $\mathrm{T}$ cell tolerance. A murine model of drug-induced lupus. $\mathbf{J} \quad \mathrm{Clin}$ Invest, 99: 1888-1896.

Lam-Tse WK, Lernmark A, Drexhage HA (2002): Animal models of endocrine/organspecific autoimmune diseases: Do they really help us to understand human autoimmunity? Springer Semin Immunopathol, 24: 297-321.

Landewe RB, Vergouwen MS, Goeei the SG, et al. (1995): Antimalarial drug induced 
decrease in creatinine clearance. J Rheumatol, 22: 34-7.

Lee SJ, Silverman E, Bargman JM. (2011): The role of antimalarial agents in the treatment of SLE and lupus nephritis. Nature reviews Nephrology, 7: 718-29.

Levy Y, Rotman-Pikielny $P$, Ehrenfeld M, et al. (2009): Silicone breast implantationinduced scleroderma: Description of four patients and a critical review of the literature. Lupus, 18: 1226-1232.

Maame B. Amissah-Arthur, Caroline Gordon (2010): Contemporary treatment of systemic lupus erythematosus: an update for clinicians. Ther Adv Chronic Dis, 1: 163-175.

Menke J, Hsu MY, Byrne KT, et al. (2008): Sunlight triggers cutaneous lupus through a CSF1-dependent mechanism in MRL-Fas(lpr) mice. J Immunol, 181: 7367-79.

Mok CC, Ying KY, Tang S, et al. (2004): Predictors and outcome of renal flares after successful cyclophosphamide treatment for diffuse proliferative lupus glomerulonephritis. Arthritis Rheum, 50: 2559-2568.

Mooij P, de Wit HJ, Drexhage HA (1993): An excess of dietary iodine accelerates the development of a thyroidassociated lymphoid tissue in autoimmune prone BB rats. Clin Immunol Immunopathol, 69: 189-98.

Morel L. (2004): Mouse Models of Human Autoimmune Diseases: Essential Tools That Require the Proper Controls. PLoS Biol, 2: e241.

Murphy GE and Swift HF. (1949): Induction of cardiac lesions, closely resembling those of rheumatic fever, in rabbits following repeated skin infections with group A streptococci. J Exp Med, 89: 687-98.

Murugadoss S, Lison D, Godderis L, et al. (2017): Toxicology of silica nanoparticles: an update. Arch Toxicol, 91: 2967-3010.

Olofsson $\mathbf{P}$ and Holmdahl R, 2007. Pristane-induced arthritis in the rat. Methods Mol Med, 136: 255-68.

Østensen M, Khamashta M, Lockshin M, et al., 2006. Antiinflammatory and immunosuppressive drugs and reproduction. Arthritis Res Therapy, 8: 209.

Otsuki T, Sakaguchi H, Tomokuni A, et al. (1998): Soluble Fas mRNA is dominantly expressed in cases with silicosis. Immunology, 94: 258-262. 
Paul-Clark M, Del Soldato P, Fiorucci S, et al. (2000): 21NO-prednisolone is a novel nitric oxide-releasing derivative of prednisolone with enhanced anti-inflammatory properties. $\mathrm{Br}$ J Pharm, 131: 1345-1354.

Pec'anac M, Janjic' Z, Komarcevic' A, et al. (2013): Burns treatment in ancient times. Med. Pregl, 66: 263-267.

Pfau JC, Brown JM, Holian A. (2004): Silica-exposed mice generate autoantibodies to apoptotic cells. Toxicology, 195: 167-176.

Pfau JC, Sentissi JJ, Li S, et al. (2008): Asbestos-induced autoimmunity in C57BL/6 mice. J Immunotoxicol, 5: 129-37.

Pollard KM (2016): Silica, silicosis, and autoimmunity. Front Immunol, 7: 97.

Pollard KM, Hultman P, Kono DH. (2010): Toxicology of autoimmune diseases. Chem Res Toxicol, 23: 455-66.

Pordeus V, Szyper-Kravitz M, Levy RA, et al. (2008): Infections and autoimmunity: a panorama. Clin Rev Allergy Immunol, 34: 283-99.

Qasim FJ, Thiru S, Gillespie K. (1997): Gold and Dpenicillamine induce vasculitis and up-regulate mRNA for IL-4 in the Brown Norway rat: support for a role for Th2 cell activity. Clin Exp Immunol, 108: 438-45.

Ramadan G, El-Beih NM, Talaat RM, et al. (2017): Antiinflammatory activity of green versus black tea aqueous extract in a rat model of human rheumatoid arthritis. Int JRheum Dis, 20: 203-213.

Reeves WH, Lee PY, Weinstein JS, et al. (2009): Induction of autoimmunity by pristane and other naturally occurring hydrocarbons. Trends Immunol, 30: 455-64.

Rogers NJ, Lees MJ, Gabriel L, et al. (2009): A defect in Marco expression contributes to systemic lupus erythematosus development via failure to clear apoptotic cells. J Immunol, 182: 1982-1990.

Rosen A, Casciola-Rosen L. (1999): Autoantigens as substrates for apoptotic proteases: implications for the pathogenesis of systemic autoimmune disease. Cell Death Differ, 6: 6-12.

Rosenthal R, Luettig J, Hering NA, et al. (2017): Myrrh exerts barrier-stabilising and-protective effects in HT-29/B6 and Caco-2 intestinal epithelial cells. Int $\mathrm{J}$ Colorectal Dis, 32: 623-634.

Rubin RL, 2005. Drug-induced lupus. Toxicology, 209: 135-47.

Segal-Eiras A, Segura GM, Babini JC, et al. (1985): Effect 
of antimalarial treatment on circulating immune complexes in rheumatoid arthritis. $\mathbf{J}$ Rheumatol, 12: 87-9.

Semwal RB, Semwal DK, Combrinck S, et al. (2015): Gingerols and shogaols: Important nutraceutical principles from ginger. Phytochemistry, 117: 554-568.

Shalaby MA and Hammouda A AE. (2014): Analgesic, antiinflammatory and antihyperlipidemic activities of Commiphora molmol extract (Myrrh). J Ethnopharmacol, 3: 56.

Shen T, Li GH, Wang XN, et al. (2012): The genus Commiphora: a review of its traditional uses, phytochemistry and pharmacology. J Ethnopharmacol, 142: 319-330.

Sobel ES, Wang F, Butfiloski E, et al. (2006): Comparison of chlordecone effects on autoimmunity in (NZBxNZW) $\mathrm{F}(1)$ and $\mathrm{BALB} / \mathrm{c}$ mice. Toxicology, 218: 81-9.

Steenland $K$ and Goldsmith DF. (1995): Silica exposure and autoimmune diseases. Am J lnd Med, 28: 603-608.

Stillwell TJ, Benson RC, DeRemee RA, et al. (1988): Cyclophosphamide-induced bladder toxicity in Wegener's granulomatosis. Arthritis Rheum, 31: 465-470.
Su S, Duan J, Chen T, et al. (2015): Frankincense and myrrh suppress inflammation via regulation of the metabolic profiling and the MAPK signaling pathway. Sci Rep, 5: $1-14$.

Su S, Hua Y, Wang Y, et al. (2012): Evaluation of the antiinflammatory and analgesic properties of individual and combined extracts from Commiphora myrrha, and Boswellia carterii. J Ethnopharmacol, 139: 649-656.

Tang L and Cheng J. (2013): Nonporous Silica Nanoparticles for Nanomedicine Application. Nano Today, 8: 290-312.

Tarleton RL, Reithinger R, Urbina JA, et al. (2007): The challenges of Chagas Diseasegrim outlook or glimmer of hope. PLoS Med, 4: e332.

Taylor PC, Quattrocchi E, Mallett S, et al., 2011. Ofatumumab, a fully human anti-CD20 monoclonal antibody, in biological-naive, rheumatoid arthritis patients with an inadequate response to methotrexate: a randomised, double-blind, placebocontrolled clinical trial. Ann Rheum Dis, 70: 2119-2125.

Teng X, Shan Z, Teng W, et al. (2009): Experimental study on the effects of chronic iodine excess on thyroid function, structure, and autoimmunity in 
autoimmune-prone NOD. H-2h4 mice Clin Exp Med, 9: 51-9.

Thakur SA, Beamer CA, Migliaccio CT, et al. (2009): Critical role of MARCO in crystalline silicainduced pulmonary inflammation. Toxicol Sci, 108: 462-71.

Tong $L$ and Moudgil KD. (2007): Celastrus aculeatus Merr. suppresses the induction and progression of autoimmune arthritis by modulating immune response to heat-shock protein 65. Arthritis ResTher, 9: R70.

Uchiyama Y, Yorozu $\mathbf{K}$, Hashizume M, et al. (2008): Tocilizumab, a humanized antiinterleukin-receptor antibody, ameliorates joint swelling in established monkey collageninduced arthritis. Biol Pharm Bull, 31: 1159-1163.

van der Goes MC, Jacobs JW, Bijlsma JW. (2014): The value of glucocorticoid co-therapy in different rheumatic diseases positive and adverse effects. Arthritis Res Ther, 16: S2.
Vas $J$ and Monestier $M$.

(2008): Immunology of mercury. Ann N Y Acad Sci, 1143: 240-67.

Verweij CL and Vosslamber S. (2011): New insight in the mechanism of action of rituximab: the interferon signature towards personalized medicine. Discov Med, 12: 229-236.

Yildirim-Toruner $\mathrm{C}$ and Diamond B. (2011): Current and novel therapeutics in the treatment of systemic lupus erythematosus. J Allergy Clin Immuno, 127: 303-12.

Yoshitomi H, Sakaguchi N, Kobayashi K, et al. (2005): A role for fungal \{beta\}-glucans and their receptor Dectin- 1 in the induction of autoimmune arthritis in genetically susceptible mice. J Exp Med, 201: 949-60.

Zheng Z, Sun Y, Liu Z, et al. (2015): The effect of curcumin and its nanoformulation on adjuvant-induced arthritis in rats. Drug Des Dev Ther, 9: 4931-4942. 